\title{
CORRECTION
}

View Article Online

View Journal I View Issue

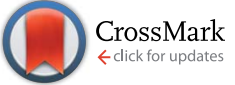

Cite this: RSC Adv., 2015, 5, 96927

DOI: $10.1039 / c 5 r a 90100 f$

www.rsc.org/advances

\section{Correction: One-shot carboxylation of microcrystalline cellulose in the presence of nitroxyl radicals and sodium periodate}

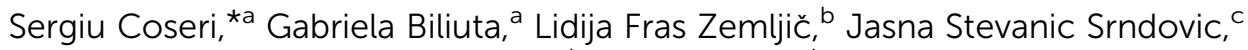

Per Tomas Larsson, ${ }^{\mathrm{c}}$ Simona Strnad, ${ }^{\mathrm{b}}$ Tatjana Kreže, ${ }^{\mathrm{b}}$ Ali Naderi ${ }^{\mathrm{c}}$ and Tom Lindström ${ }^{\mathrm{c}}$

Correction for 'One-shot carboxylation of microcrystalline cellulose in the presence of nitroxyl radicals and sodium periodate' by Sergiu Coseri et al., RSC Adv., 2015, 5, 85889-85897.

The authors regret that the images presented for Fig. 1 and 3 in the original article present incorrect carbohydrate structures. The amended versions of these images, in which the 3-position hydroxyl groups are equatorial rather than axial, are presented below.

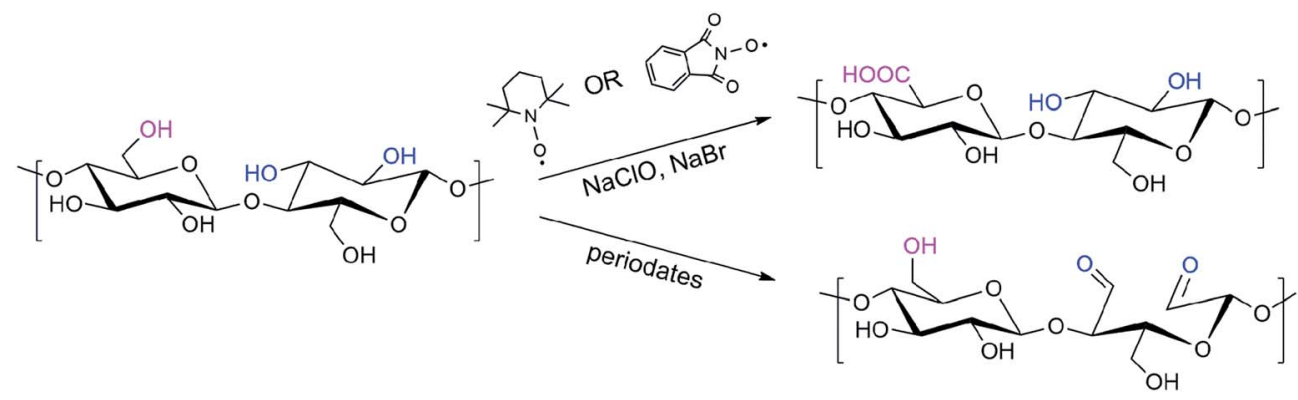

Fig. 1 Possible oxidation routes for cellulose selective oxidation, in the presence of nitroxyl radicals or periodates.

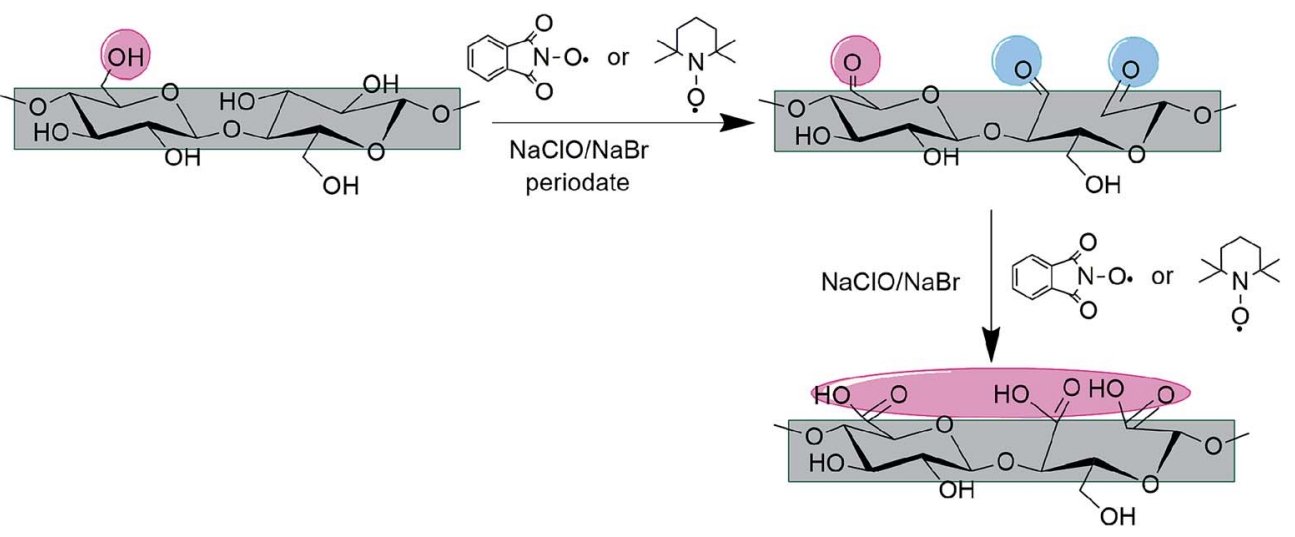

Fig. 3 Illustration scheme of the full oxidation of cellulose in the presence of both nitroxyl radical (TEMPO or PINO) and periodate.

The Royal Society of Chemistry apologises for these errors and any consequent inconvenience to authors and readers.

a“Petru Poni" Institute of Macromolecular Chemistry of Romanian Academy, Members of the European Polysaccharide Network of Excellence (EPNOE), 41 A, Gr. Ghica Voda Alley, 700487, Iasi, Romania. E-mail: coseris@icmpp.ro; Fax: +40 232 211299; Tel: +40 232217454

${ }^{b}$ Laboratory for Characterization and Processing of Polymers, Faculty of Mechanical Engineering, University of Maribor, Members of the European Polysaccharide Network of Excellence (EPNOE), Smetanova 17, SI-2000 Maribor, Slovenia

'Innventia AB, Drottning Kristinas väg 61, Box 5604, SE-114 86 Stockholm, Sweden 